\title{
Prostaatspecifiek membraanantigeen radioligandtherapie met alfastralers, een review
}

\author{
Bastiaan M. Privé · Willemijn A. M. van Gemert · James Nagarajah · Niven Mehra · Winald R. Gerritsen · \\ Inge M. van Oort · Martin Gotthardt · Sandra Heskamp · Marcel J. R. Janssen
}

Published online: 26 August 2020

(C) The Author(s) 2020

Samenvatting Prostaatspecifiek membraanantigeen (PSMA) radioligandtherapie is een veelbelovende experimentele behandeling voor gemetastaseerd prostaatcarcinoom. In de nog lopende fase III-studie wordt lutetium-177 ( $\left.{ }^{177} \mathrm{Lu}\right)$-PSMA, een bètastraler, gebruikt. Er wordt momenteel echter ook op beperkte schaal geëxperimenteerd met alfastralers die zijn gekoppeld aan PSMA-liganden, met name actinium-225 $\left({ }^{225} \mathrm{Ac}\right)$-PSMA. In vergelijking met bètastralers leiden alfastralers tot moeizamer herstellende DNA-schade, waarmee ze mogelijk effectiever zijn en een betere immunologische respons geven. Daarnaast hebben alfastralers een veel geringer doordringend vermogen, wat een voordeel zou kunnen zijn bij patiënten met diffuse beenmergmetastasering en bij patiënten met micrometastasen. De bijwerkingen op de speekselklieren zijn echter waarschijnlijk wel ernstiger. Net als bij bèta-PSMA-therapie is alfa-PSMA-therapie vooralsnog experimenteel. Het effect van alfastralers is enkel onderzocht in retrospectieve series - er zijn nog geen prospectieve of vergelijkende studies verricht waardoor de resultaten voorzichtig moeten worden geïnterpreteerd. De wereldwijde productie van ${ }^{225} \mathrm{Ac}$ en andere alfastralers zou bovendien fors moeten worden opgeschaald om klinische studies en grootschalig gebruik mogelijk te maken. In deze review

drs. B. M. Privé $(\varangle) \cdot$ dr. W. A. M. van Gemert • prof. dr. J. Nagarajah · prof. dr. M. Gotthardt .

dr. S. Heskamp · dr. M. J. R. Janssen

afdeling Radiologie en Nucleaire Geneeskunde,

Radboudumc, Nijmegen, Nederland

bastiaan.prive@radboudumc.nl

dr. N. Mehra · prof. dr. W. R. Gerritsen

afdeling Medische Oncologie, Radboudumc, Nijmegen,

Nederland

dr. I. M. van Oort

afdeling Urologie, Radboudumc, Nijmegen, Nederland geven we een overzicht van de eerste klinische data omtrent alfa-PSMA-therapie.

Trefwoorden actinium-225-PSMA · alfastraling · gemetastaseerd prostaatcarcinoom - PSMA-therapie . review

\section{Prostate-specific membrane antigen radioligand therapy with alpha emitters, a review}

Abstract Prostate-specific membrane antigen (PSMA) radioligand therapy is a novel treatment for castration-resistant prostate cancer (mCRPC). Currently, most data on PSMA radioligand therapy refer to ${ }^{177} \mathrm{Lu}-$ PSMA, a beta emitter. However, PSMA ligands can also be labelled to alpha emitting radionuclides, such as ${ }^{225} \mathrm{Ac}$. Compared to beta emitters, alpha decay induces more harmful DNA damage. Thus, alpha emitter labelled PSMA ligands may have a better therapeutic effect compared to their beta emitting counterparts. Moreover, alpha decay has a much shorter linear energy transfer which could be beneficial in patients with micrometastases or diffuse bone-marrow infiltration. However, alfa-PSMA radioligand therapy is still experimental as there is only retrospective data available and prospective studies are awaited. Hence, the results require to be interpreted with caution. Also, production of ${ }^{225} \mathrm{Ac}$ and other alpha emitting isotopes needs to be increased significantly before clinical application. In this review, we summarize and discuss the current developments on alfa-PSMA radioligand therapy.

Keywords actinium-225-PSMA · alpha emitters · prostate cancer $\cdot$ PSMA-therapy $\cdot$ review 


\section{Introductie}

Zoals recent beschreven in het Tijdschrift voor Urologie zijn er diverse nieuwe therapieën in ontwikkeling voor patiënten met gemetastaseerd castratieresistent prostaatcarcinoom (mCRPC) [1]. Eén hiervan is radioligandtherapie. Bij radioligandtherapie worden tumorcellen lokaal bestraald met radioactieve stoffen. De stof die de radioactieve straling afgeeft, wordt het radionuclide genoemd. Om het radionuclide in de tumorcel te krijgen, moet het worden gekoppeld aan een molecuul dat de tumorcellen herkent, het zogenaamde ligand. Historisch gezien werden dit soort therapieën vooral gebruikt bij schildkliercarcinoom en goed gedifferentieerde neuro-endocriene tumoren, beide relatief zeldzaam [2]. Met de introductie van radium-223 $\left({ }^{223} \mathrm{Ra}\right)$ voor de behandeling van patiënten met ossaal gemetastaseerd castratieresistent prostaatcarcinoom werd radionuclidetherapie voor het eerst met succes op grote schaal toegepast. Dit heeft geleid tot groeiende aandacht voor het ontwikkelen van nieuwe therapeutische radioliganden.

Bij prostaatcarcinoom is het prostaatspecifiek membraanantigeen (PSMA) een veelbelovend target voor radioligandtherapie (fig. 1). $\mathrm{Bij}>90 \%$ van de prostaatcarcinomen wordt in verhoogde mate PSMA aangetroffen op de celmembraan. De mate van PSMA-expressie lijkt verder toe te nemen met het vorderen van het ziektestadium en met het toenemen van de tumoragressiviteit. Daarnaast is de PSMAexpressie in de meeste andere weefsels laag [2, 3].

De laatste jaren worden bij prostaatkankerdiagnostiek steeds vaker PET/CT-scans ingezet, die positronstraling zichtbaar kunnen maken. De positronstraling wordt in dit geval afgegeven door liganden die via een intraveneuze injectie zijn verrijkt met een diagnostisch radionuclide, zoals gallium-68 $\left({ }^{68} \mathrm{Ga}\right)$ en fluor$18\left({ }^{18} \mathrm{~F}\right)$. Deze diagnostische PSMA-radioliganden worden na intraveneuze injectie snel in de prostaatkan-

Figuur 1 a ${ }^{68} \mathrm{Ga}-\mathrm{PSMA}-\mathrm{PET} / \mathrm{CT}-\mathrm{scan}$ voorafgaand aan ${ }^{225}$ Ac-PSMA-617 van een patiënt met castratieresistent prostaatcarcinoom (niet PSA-producerend). b Na zes maanden (3 cycli ${ }^{225}$ Ac-PSMA-617) heeft de patiënt matig gereageerd op de behandeling. Hij startte met cabazitaxel-carboplatin, maar overleed 10 maanden na start van ${ }^{225} \mathrm{Ac}-\mathrm{PSMA}-617$. c ${ }^{68} \mathrm{Ga}-\mathrm{PSMA}-\mathrm{PET} / \mathrm{CT}-\mathrm{scan}$ van een gemetastaseerde patiënt die in de castratieresistente fase reeds was behandeld met abiraterone, docetaxel, ${ }^{223} \mathrm{Ra}$ en enzalutamide. d PSMAPET/CT-scan van dezelfde patiënt na drie cycli met $6,4 \mathrm{MBq}$ ${ }^{225}$ Ac-PSMA-617 (om de 8 weken), waarop een partiële respons te zien is, zowel qua imaging $\left({ }^{68} \mathrm{Ga}-\mathrm{PSMA} \mathrm{PET} / \mathrm{CT}\right)$ als PSA-daling (van $2600 \mu \mathrm{g} / \mathrm{I}$ naar $50 \mu \mathrm{g} / \mathrm{l}$ ). De patiënt overleed uiteindelijk 18 maanden na de start van de ${ }^{225} \mathrm{Ac}-\mathrm{PSMA}-$ therapie. e $^{68} \mathrm{Ga}-\mathrm{PSMA}-\mathrm{PET} / \mathrm{CT}$-scan van een patiënt die in de castratieresistente fase reeds was behandeld met abiraterone, docetaxel, enzalutamide, cabazitaxel en ${ }^{223} \mathrm{Ra}$. f $\mathrm{Na} 6$ maanden heeft de patiënt een zeer goede respons op ${ }^{225} \mathrm{Ac}$ PSMA-617. Het PSA is gedaald van $790 \mu \mathrm{g} / \mathrm{l}$ naar $2,1 \mu \mathrm{g} / \mathrm{l}$. De patiënt is na drie jaar nog in leven en heeft nadien nog meer cycli PSMA-therapie gehad kercellen opgenomen en blijven ook geruime tijd in de tumorcellen, terwijl de meeste gezonde weefsels relatief weinig van deze radioliganden opnemen (op met name de speekselklieren na). Door de snelle klaring via de nieren of lever - afhankelijk van het gebruikte ligand - en door opname van het radioligand in de tumor is de plasmaspiegel al snel weer laag. Er vindt dus een snelle en goede verdeling van het radioligand plaats tussen prostaatkankerlaesies en gezonde weefsels. Deze maakt het mogelijk om agressievere straling (alfa- of bètastraling) aan het PSMA-ligand te koppelen, niet zozeer met het doel de tumor zichtbaar te maken, maar juist om de tumor lokaal te bestralen.

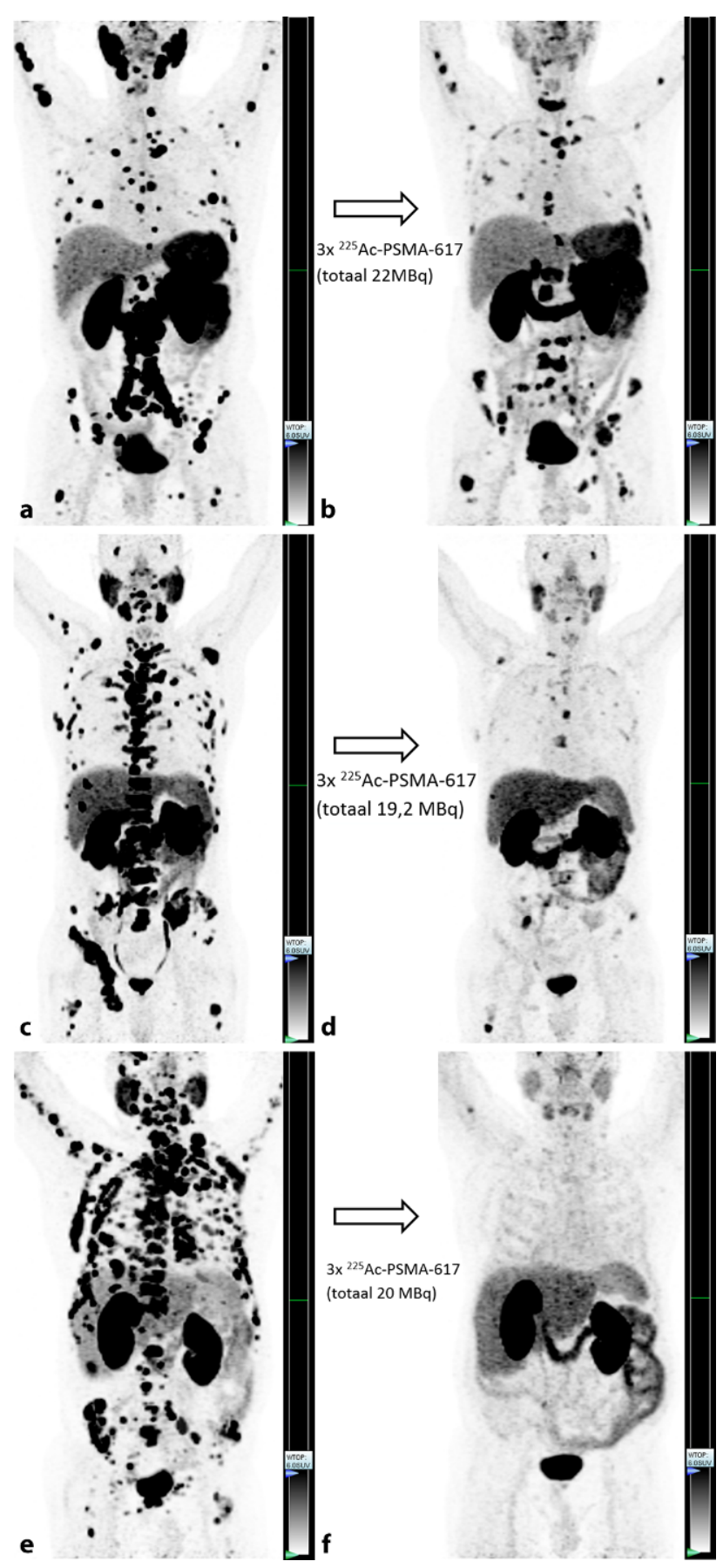


Er is inmiddels met name ervaring opgedaan met de vooralsnog experimentele lutetium-177 $\left({ }^{177} \mathrm{Lu}\right)$ gelabelde PSMA-liganden, oftewel ${ }^{177} \mathrm{Lu}$-PSMA. De ontwikkeling van ${ }^{177} \mathrm{Lu}$-PSMA-therapie is ongewoon verlopen, doordat na de eerste veelbelovende resultaten (proof of principle) er met name in Duitsland een uitgebreid compassionate use programma op gang is gekomen zonder dat er formele fase I-, II- en III-studies waren uitgevoerd. Dit maakt dat in de lekenpers ${ }^{177} \mathrm{Lu}-\mathrm{PSMA}$ al geruime tijd onterecht als een routinetherapie wordt beschouwd, hetgeen tot ingewikkelde discussies kan leiden op de polikliniek.

Inmiddels zijn er enkele prospectieve studies uitgevoerd met ${ }^{177} \mathrm{Lu}-\mathrm{PSMA}$ en is de registratiestudie voor ${ }^{177} \mathrm{Lu}-\mathrm{PSMA}-617$ door patenthouder Novartis (NCT03511664; VISION trial) in de follow-upfase. Er wordt dan ook door velen uitgekeken naar de eerste resultaten van deze studie. De hoop is dat de uitkomst zodanig zal zijn dat de registratie van ${ }^{177} \mathrm{Lu}-$ PSMA zal volgen voor de behandeling van patiënten die al meerdere therapieën in de castratieresistente fase hebben gehad. Zie ook [4].

Het PSMA-ligand kan echter niet alleen met een bètastraler, zoals ${ }^{177} \mathrm{Lu}$, maar ook met een alfastraler worden gelabeld. Met alfastralende versies van het PSMAradioligand is nog veel minder ervaring dan met bètastralende versies. Deze therapie is dan ook nog hoogst experimenteel, hoewel ook voor deze therapie in Duitsland op beperkte schaal een compassionate use programma bestaat, waardoor ook deze therapie tot vragen op het Nederlandse spreekuur leidt. Bovendien zou alfa-PSMA-therapie op theoretische gronden effectiever kunnen zijn dan ${ }^{177} \mathrm{Lu}-\mathrm{PSMA}$, zeker voor een aantal specifieke patiëntengroepen.

Dit artikel gaat in op de verschillen tussen alfa- en bètastraling en beschrijft de eerste ervaringen met alfastralende PSMA-liganden.

\section{De belangrijkste verschillen tussen alfa- en bètastraling}

Bij radioactieve stoffen is de atoomkern instabiel. Dit komt meestal doordat de verhouding tussen het aantal protonen en neutronen niet goed is. De atoomkern zal naar een stabielere toestand willen gaan en bij het veranderen van de samenstelling van de kern komt radioactieve straling vrij. In de kliniek zijn gammastraling en de positronbèta ${ }^{+}$-straling het meest bekend. Gammastraling kan worden waargenomen door een gammacamera (denk aan de traditionele botscan) en bèta ${ }^{+}$-straling door PET/CT-scanners. Beide soorten straling zijn geschikt voor diagnostiek, maar voor therapie zijn ze niet ioniserend genoeg.

Bij alfa- en bètastraling komen deeltjes (met massa) vrij uit de atoomkern. Deze deeltjes beschadigen DNA-strengen en kunnen daarom worden gebruikt voor therapie. Bij bètastraling schieten er elektronen uit de vervallende atoomkern. Elektronen zijn zulke kleine deeltjes dat ze meestal enkelstrengs DNA-breu- ken veroorzaken. Omdat de complementaire DNAstreng nog intact is, kan de cel dit soort schade redelijk goed herstellen, mits de DNA-repairenzymen normaal functioneren. Daarom zijn bij bètastralende radioliganden meestal enkele honderden beschadigingen aan een DNA-streng nodig om tot celdood te leiden. Door hun geringe grootte kunnen elektronen daarentegen wél enkele millimeters diep doordringen in weefsel; zij botsen immers niet zo snel ergens tegenaan, en raken bij een botsing meestal ook niet al hun energie in één keer kwijt. Hoe ver zij in het lichaam kunnen doordringen, varieert per radioactieve stof. Bij de in praktijk gebruikte bètastralers ligt het maximale doordringend vermogen (ofwel de 'dracht') doorgaans rond de $1-10 \mathrm{~mm}$. Bij het bètastralende ${ }^{177} \mathrm{Lu}-\mathrm{PSMA}$ is de dracht $1-2 \mathrm{~mm}$ [5].

Bij alfastraling schieten er veel grotere deeltjes uit de vervallende atoomkern, namelijk brokjes bestaande uit twee neutronen en twee protonen. Een alfadeeltje heeft meer dan 7.000 keer zoveel massa als een elektron. Daardoor veroorzaken alfadeeltjes meestal dubbelstrengs DNA-breuken, die veel slechter door de cel hersteld kunnen worden. Daardoor zijn één of twee hits vaak al genoeg om een cel te doden. Het doordringend vermogen van de alfadeeltjes is echter gering: ze zijn zo groot dat ze al snel tegen iets aanbotsen. Hoewel ze bij zo'n botsing ter plekke veel schade veroorzaken, komen ze bij de botsing ook tot stilstand: het alfastralende actinium-225 $\left({ }^{225} \mathrm{Ac}\right)$ PSMA heeft een doordringend vermogen van slechts 40-100 $\mu \mathrm{m}$ (enkele cellagen) [5].

Als alfastraling de tumor bereikt, is de tumorschade dus potentieel groot, maar dat geldt ook voor de schade in gezonde weefsels die PSMA stapelen (zoals de speekselklieren), waardoor ook sprake is van meer bijwerkingen dan bij bètastraling. Omdat de alfastraling maar een gering doordringend vermogen heeft, is het effect ervan heel lokaal en is er nauwelijks uitsmering rondom de metastasen. Bij uitgebreid gemetastaseerde ziekte is de korte alfadracht vaak niet klinisch-relevant, maar er zijn twee situaties waarbij dit wel relevant kan zijn. Ten eerste bij patiënten met diffuse beenmergmetastasering. Hier is het van belang zo weinig mogelijk van de nog gezonde beenmergcellen te raken waardoor de korte dracht van de alfastraling juist een voordeel kan zijn [5]. Momenteel is forse beenmergmetastasering een relatieve contra-indicatie voor ${ }^{177} \mathrm{Lu}$-PSMA-therapie, omdat de beenmergtoxiciteit bij deze subcategorie patiënten hoog kan zijn. Een ander potentieel voordeel van de beperkte dracht van alfastraling doet zich voor bij de groep patiënten met microscopische metastasen. Voor ${ }^{177} \mathrm{Lu}-\mathrm{PSMA}$-therapie ligt op theoretische gronden de optimale grootte van een metastase op 1-3 mm. Bij kleinere metastasen komt bij bètastraling naar verhouding een steeds groter deel van de straling rondom de metastase vrij in plaats van in de metastase, door de uitsmering ten gevolge van het doordringend vermogen van meerdere millimeters 
van de bètastraling. Bij de zeer korte dracht van alfastraling komt echter ook bij kleinere metastasen nog steeds het merendeel van de straling in de metastase vrij. Overigens kan de geringe dracht potentieel ook nadelig zijn bij heterogene PSMA-expressie in het tumorweefsel. Dit komt doordat bij korte alfadracht de tumorcellen zonder PSMA-expressie niet kunnen worden bestraald vanuit naburige tumorcellen met PSMA-expressie. Hoewel dit bij grotere gebieden zonder PSMA-expressie natuurlijk ook met de grotere bètadracht al snel niet meer lukt. Het zoeken naar heterogeniteit en gebieden met vitale tumor zonder PSMA-expressie is dan ook relevant bij het stellen van de indicatie voor PSMA-radioligandtherapie [6].

Verder zijn er in preklinisch onderzoek aanwijzingen dat er bij bestraling met alfadeeltjes meer tumoreiwitten vrijkomen dan bij bestraling met bètadeeltjes. Dit zou kunnen betekenen dat alfatherapie een betere immuunrespons op gang kan brengen, hetgeen ook in combinatie met de opkomende immunotherapie zeer interessant kan zijn [7].

\section{Alfa-PSMA-therapie met ${ }^{225}$ Ac-PSMA}

Met alfa-PSMA-therapie is nog maar weinig ervaring. Momenteel wordt het meest gebruikgemaakt van ${ }^{225}$ Ac-PSMA, dat in studieverband of op kleine schaal in compassionate use programma's (met name in Duitsland) gegeven wordt. ${ }^{225}$ Ac-PSMA wordt, net als ${ }^{177} \mathrm{Lu}-\mathrm{PSMA}$, gegeven als een langzame intraveneuze bolusinjectie. Patiënten verblijven daarna meestal maximaal 24 uur in het ziekenhuis. Echter, dit is afhankelijk van de lokale stralingshygiënische regels. Zo duurt de opname in Duitsland 48 uur. Het stralingsniveau rondom de patiënt is direct na de injectie zeer laag, doordat de straling nauwelijks door de patiënt naar buiten komt. Hierdoor kunnen nauwelijks scans worden gemaakt van de verdeling van ${ }^{225}$ Ac-PSMA in het lichaam. Net als bij ${ }^{177}$ Lu-PSMA wordt het merendeel van het PSMA dat niet wordt opgenomen renaal geklaard, dus de urine bevat zeker de eerste twee dagen aanzienlijke hoeveelheden radioactiviteit. Bij patiënten die goed reageren op de eerste cyclus worden meestal drie tot vier cycli ${ }^{225} \mathrm{Ac}$-PSMA gegeven. Een dosismetriestudie van 14 patiënten waarin 50, 100 en $150 \mathrm{kBq} / \mathrm{kg}$ lichaamsgewicht werd gebruikt, suggereerde dat $100 \mathrm{kBq} / \mathrm{kg}{ }^{225} \mathrm{Ac}$-PSMA de optimale dosering is. De effectiviteit van $100 \mathrm{kBq} / \mathrm{kg}$ was hoger dan van $50 \mathrm{kBq} / \mathrm{kg}$, maar verder verhogen naar $150 \mathrm{kBq} / \mathrm{kg}$ gaf meer toxiciteit zonder duidelijke verbetering van de effectiviteit [8]. Voor een man van $80 \mathrm{~kg}$ zou dat $8 \mathrm{MBq}{ }^{225} \mathrm{Ac}$-PSMA zijn, terwijl voor ${ }^{177} \mathrm{Lu}-\mathrm{PSMA} 7,4 \mathrm{GBq}$ gebruikelijk is. Er dient dus benadrukt te worden dat er bij ${ }^{225}$ Ac-PSMA-therapie ongeveer een factor 1.000 minder radioactiviteit wordt toegediend. Overigens is het vervalproduct van ${ }^{225} \mathrm{Ac}$ ook niet stabiel en vervalt dit weer verder in een hele cascade, zodat er in totaal vier alfadeeltjes en twee bètadeeltjes vrijkomen. Omdat het ${ }^{225} \mathrm{Ac}$-PSMA geïnternaliseerd wordt in de prostaatkankercel komt waarschijnlijk het merendeel van deze deeltjes in de cel vrij (zonder dus opnieuw te verdelen over de rest van het lichaam) en vermoedelijk dragen zij dan ook allemaal bij aan het therapeutisch effect. Maar er is meer onderzoek nodig om dit te bevestigen.

Er zijn twee series gepubliceerd van patiënten met mCRPC die met ${ }^{225}$ Ac-PSMA werden behandeld $[9,10]$. De eerste is een Duitse serie van Kratochwil et al. waarin 40 uitbehandelde patiënten met mCRPC in Heidelberg werden behandeld met in principe drie cycli van $100 \mathrm{kBq} / \mathrm{kg}{ }^{225} \mathrm{Ac}$-PSMA. Dit is een redelijk homogene serie patiënten met eindstadiumziekte. Dat bleek ook uit het feit dat van de 45 geselecteerde patiënten er vijf overleden in de wachttijd (van maximaal 8 weken) voor de eerste cyclus ${ }^{225}$ Ac-PSMA-therapie. Alle patiënten hadden bij baseline een goede PSMAligandopname op de PSMA-PET/CT (dit was een inclusiecriterium). In totaal werden 31 van de 40 patiënten volgens studieprotocol met de volledige drie cycli ${ }^{225}$ Ac-PSMA behandeld. Vijf patiënten stopten met de behandeling omdat er geen respons optrad na de eerste cyclus. Vier patiënten stopten vanwege de bijwerking xerostomie (droge mond). Van de 38 patiënten die minimaal één cyclus hadden ontvangen, liet $87 \%$ een PSA-daling zien en bij $63 \%$ van de patiënten was er een PSA-daling van $>50 \%$. De mediane progressievrije overleving was negen maanden. Bovendien hadden vijf patiënten een bijna complete PSA-respons en bleven zij na behandeling nog meer dan twee jaar in remissie, wat erg indrukwekkend is bij uitbehandelde patiënten [9]. Overigens beschikte men in Heidelberg zowel over ${ }^{177} \mathrm{Lu}$-PSMA als ${ }^{225} \mathrm{Ac}$ PSMA en werden juist de ziekere patiënten (hoge tumorload, diffuse beenmergmetastasering, snelle progressie, viscerale metastasen) geselecteerd voor ${ }^{225} \mathrm{Ac}-$ PSMA. Zo hadden 18 van de 40 patiënten in deze serie diffuse beenmergmetastasering waardoor zij niet in aanmerking kwamen voor ${ }^{177} \mathrm{Lu}-\mathrm{PSMA}$. Er lijkt in deze serie dus een overrepresentatie van ziekere patiënten, maar desondanks werden goede resultaten behaald.

In een tweede serie (uit Zuid-Afrika) van Sathekge et al. werden 73 patiënten met mCRPC behandeld met een sterk wisselend aantal cycli en wisselende doseringen ${ }^{225} \mathrm{Ac}$-PSMA. In totaal werden 210 cycli gegeven; de meerderheid van de patiënten ontving twee tot vijf cycli, tot maximaal acht cycli bij één patiënt. $82 \%$ van de patiënten had een PSA-respons en bij $70 \%$ van de patiënten trad een PSA-daling op van meer dan $50 \%$. De geschatte mediane progressievrije overleving was 15,2 maanden [10]. Bij deze serie patiënten moet echter worden vermeld dat zij niet alle geregistreerde therapielijnen hebben gehad, omdat deze middelen ter plaatse (Zuid-Afrika) beperkte beschikbaar waren. Zo had maar $50 \%$ van de patiënten chemotherapie gekregen en zelfs maar één patiënt abiraterone of enzalutamide. Daarentegen waren deze patiënten wel frequent voorbehandeld met ${ }^{177} \mathrm{Lu}$-PSMA en hierop progressief gebleken, waardoor juist de minder goed reagerende 
Tabel 1 Therapie-effecten van PSMA-therapie

\begin{tabular}{|c|c|c|c|c|c|c|}
\hline Referentie & Radioligand & Activiteit & Cycli & $N$ & $\begin{array}{l}\text { Percentage }>50 \% \\
\text { PSA-reductie }\end{array}$ & $\begin{array}{l}\text { Progressievrije overleving, } \\
\text { maanden (mediaan) }\end{array}$ \\
\hline Kratochwil et al. [9] & ${ }^{225} \mathrm{AC}-\mathrm{PSMA}-617$ & $100 \mathrm{kBq} / \mathrm{kg}{ }^{225} \mathrm{Ac}$ & $1-3$ & 40 & $63 \%$ & 9 \\
\hline Sathekge et al. [10] & ${ }^{225}$ Ac-PSMA-617 & $8-4 \mathrm{MBq}{ }^{225} \mathrm{Ac}$ & $1-8$ & 73 & $70 \%$ & 15,2 \\
\hline Khreish et al. [12] & $\begin{array}{l}{ }^{177} \text { Lu-PSMA-617+ } \\
{ }^{225} \text { AC-PSMA-617 }\end{array}$ & $\begin{array}{l}6,9 \mathrm{GBq}^{177} \mathrm{Lu}+ \\
60 \mathrm{KBq} / \mathrm{kg}^{225} \mathrm{Ac}\end{array}$ & $1-5$ & 20 & $65 \%$ & 4,8 \\
\hline Hofman et al. [17] & ${ }^{177}$ Lu-PSMA-617 & $7,5 \mathrm{GBq}^{177} \mathrm{Lu}$ & 4 & 30 & $57 \%$ & 7,6 \\
\hline Rahbar et al. [16] & ${ }^{177}$ Lu-PSMA-617 & $5,9 \mathrm{GBq}^{177} \mathrm{Lu}$ & $1-4$ & 145 & $45 \%$ & - \\
\hline Heck et al. [31] & ${ }^{177}$ Lu-PSMA-I\&T & $7,4 \mathrm{GBq}^{177} \mathrm{Lu}$ & $1-6$ & 100 & $38 \%$ & 4,1 \\
\hline
\end{tabular}

patiënten in deze studie geïncludeerd werden. Dit had wellicht een negatieve invloed op de effectiviteit van ${ }^{225}$ Ac-PSMA [10]. De chemonaïeve-mCRPC patiënten uit de studie van Sathekges werden eerder apart gepubliceerd en toonden - zoals te verwachten - nóg betere resultaten (14 van de 17 patiënten hadden een PSA-daling van $>90 \%$ en bij 7 van de 17 patiënt was het PSA zelfs niet te detecteren) [11]. Deze serie kan natuurlijk niet goed worden vergeleken met uitbehandelde mCRPC-patiënten.

In tab. 1 staat een overzicht van de geobserveerde therapie-effecten van de verschillende PSMA-radioligandtherapieën. Deze series kunnen niet goed met elkaar vergeleken worden, met name doordat de populaties sterk verschillen. De resultaten moeten dus omzichtig worden geïnterpreteerd. Toch leken de 40 patiënten die in Heidelberg werden behandeld met ${ }^{225}$ Ac-PSMA aanmerkelijk zieker dan de patiënten in de ${ }^{177} \mathrm{Lu}$-PSMA-series, terwijl de resultaten vergelijkbaar tot beter zijn en er zelfs meer complete biochemische responders met een lange progressievrije overleving waren.

Daarnaast zijn er casereports van patiënten die progressief waren op ${ }^{177} \mathrm{Lu}-\mathrm{PSMA}$, maar vervolgens met ${ }^{225}$ Ac-PSMA alsnog in een langdurige goede remissie konden worden gebracht. Deze gegevens dragen bij aan de hypothese dat alfa-PSMA-therapie effectiever zou zijn dan bèta-PSMA-therapie. Binnen de nucleaire geneeskunde wordt dan ook veel verwacht van alfa-PSMA-therapie [10, 12-15].

\section{Toxiciteit}

De belangrijkste organen die risico lopen bij PSMAtherapie zijn het beenmerg en de speekselklieren, en in mindere mate de nieren.

Het beenmerg is relatief stralingsgevoelig en goed doorbloed. Hoewel de plasmaklaring snel verloopt, wordt er toch enige schade toegebracht zolang het radioligand nog in het plasma aanwezig is. Daarnaast hebben veel patiënten met prostaatkanker botmetastasen. Als de botmetastasen het radioligand opnemen, kan strooistraling vanuit de metastasen tot schade van het omringende beenmerg leiden. Op theoretische gronden wordt verwacht dat deze beenmergschade bij alfa-PSMA-therapie lager is dan bij bèta-PSMA-therapie. Beenmergdepressie valt echter niet uit te sluiten, omdat er bij patiënten met uitbehandelde prostaatkanker, door uitgebreide botmetastasering en door multipele voorgaande lijnen systeemtherapie, al een sterk verminderde beenmergreserve zal zijn opgetreden. Daarom moet voorafgaand aan elke cyclus PSMA-radioligandtherapie het bloedbeeld gecontroleerd worden. In de studie van Sathekge et al. werd bij alfa-PSMA-therapie laaggradige en hooggradige beenmergtoxiciteit gezien bij respectievelijk $30 \%$ en $7 \%$ van de patiënten [10]. Hoewel er ook qua toxiciteit geen direct vergelijkende studies zijn, lijkt de beenmergtoxiciteit bij gebruik van alfaPSMA niet hoger dan bij bèta-PSMA, en de hypothese is dat deze toxiciteit zelfs lager zal zijn in een directe vergelijking.

Dit lijkt echter anders voor de speekselklieren, waarbij de toxiciteit bij alfa-PSMA-therapie hoger lijkt dan bij bèta-PSMA-therapie. De speekselklieren hebben een zeer hoge PSMA-stapeling, waardoor ze bij PSMA-radioligandtherapie aan een relatief hoge dosis worden blootgesteld. In de serie van Sathekge werd door $85 \%$ van de patiënten laaggradige xerostomie beschreven, maar kwam er bij geen van de patiënten hooggradige xerostomie voor. In de Duitse serie van Kratochwil et al. had daarentegen $10 \%$ van de patiënten dermate ernstige xerostomie dat de behandeling moest worden gestaakt $[9,10]$. Deze ernstige toxiciteit is niet beschreven in de grotere retrospectieve series met bèta-PSMA-therapie met ${ }^{177}$ Lu-PSMA, waarbij $8 \%$ van de patiënten laaggradige xerostomie rapporteerde [16]. Bij gestructureerd scoren van xerostomie in een prospectieve studie met ${ }^{177} \mathrm{Lu}$-PSMA zijn de percentages laaggradige xerostomie weliswaar duidelijk hoger (87\% laaggradige xerostomie), maar werd geen hooggradige xerostomie waargenomen [17]. Hoewel ook de speekselkliertoxiciteit niet rechtstreeks vergeleken is, lijkt er na behandeling met meerdere cycli alfaPSMA-therapie vaker ernstige speekselkliertoxiciteit op te treden dan na meerdere cycli bèta-PSMA-therapie en dit lijkt ook plausibel. Xerostomie is een relevante bijwerking, gezien ernstige xerostomie een forse impact kan hebben op de kwaliteit van leven (droge mond, minder smaak, moeite met doorslapen, hinder tijdens praten).

Andere bijwerkingen die worden beschreven bij alfa-PSMA-therapie met ${ }^{225} \mathrm{Ac}$ zijn laag- en hooggradige nefrotoxiciteit, die in de studie van Sathekge 
et al. optraden bij respectievelijk $25 \%$ en $7 \%$ van de patiënten. Laaggradige vermoeidheid trad op bij $51 \%$ van de patiënten [10]. Vermoeidheid is een bekende bijwerking van radioligandtherapie, en wordt ook gezien bij ongeveer de helft van de patiënten na ${ }^{177} \mathrm{Lu}-$ PSMA-therapie [17]. Nefrotoxiciteit en vermoeidheid zijn echter zelden dosislimiterend, terwijl xerostomie dat wel is. Xerostomie is dan ook de primaire reden om ${ }^{225}$ Ac -PSMA enigszins voorzichtig te doseren, daar er nog geen werkzame interventies beschikbaar zijn om de speekselklieren te beschermen. Om de ${ }^{225} \mathrm{Ac}$ dosering te kunnen verlagen, maar de effectiviteit te behouden, is voorgesteld om alfa-PSMA-therapie middels ${ }^{225}$ Ac-PSMA te combineren met ${ }^{177} \mathrm{Lu}$-PSMA. Daarnaast wordt voorgesteld om bij deze combinatietherapie de ${ }^{225} \mathrm{Ac}$-dosering te de-escaleren, ofwel: ${ }^{225} \mathrm{Ac}$ bij de eerste therapie relatief hoog te doseren en bij goede respons in volgende cycli de ${ }^{225} \mathrm{Ac}$-dosering te verlagen. Deze de-escalatie geeft tevens het belang van de eerste behandeling aan. Bij patiënten met een hoge tumorload worden de speekselklieren in eerste instantie enigszins beschermd, doordat de tumor zoveel PSMA-radioligand opneemt dat er niet veel meer beschikbaar is voor de speekselklieren en de speekselklierdosis nog beperkt blijft. Bij goede respons en sterke afname van de tumormassa verdwijnt dit beschermende effect en neemt de speekselkliertoxiciteit toe. Theoretisch zijn er meer argumenten om te focussen op de eerste cyclus. Bijvoorbeeld dat er nog geen klonale selectie kan zijn van tumorcellen met lage PSMA-expressie. Samengevat lijkt de eerste cyclus zowel het meest effectief als het minst toxisch. Derhalve lijken combinatietherapieën van ${ }^{225} \mathrm{Ac}$-PSMA en ${ }^{177} \mathrm{Lu}$-PSMA met zo mogelijk een geleidelijk afnemende ${ }^{225} \mathrm{Ac}$-dosering zeker aantrekkelijk, en uitnodigend voor verdere verkenning [12].

\section{Uitdagingen bij ${ }^{225}$ Ac-PSMA-therapie}

Zoals hiervoor beschreven, zijn er vooralsnog alleen retrospectieve studies in kleine patiëntenpopulaties gepubliceerd over ${ }^{225}$ Ac-PSMA-therapie. De resultaten van deze series moeten dus met voorzichtigheid worden geïnterpreteerd. Er is behoefte aan meer klinische data en goed opgezet prospectief klinisch onderzoek. Op ClinicalTrials.gov staan de resultaten beschreven van twee lopende ${ }^{225}$ Ac-PSMA-studies (NCT03276572 \& NCT04225910). Het Erasmus MC kreeg in 2019 een beurs om een klinische studie met ${ }^{225}$ Ac-PSMA op te starten. Het belangrijkste probleem op het gebied van alfa-PSMA-therapie is echter de extreem beperkte beschikbaarheid van ${ }^{225} \mathrm{Ac}$. De wereldwijde productie van ${ }^{225} \mathrm{Ac}$ is momenteel slechts toereikend voor enkele honderden patiënten per jaar. De productie is op dit moment ook niet direct te verhogen aangezien het ${ }^{225} \mathrm{Ac}$ afkomstig is uit verval van uranium-233 $\left({ }^{233} \mathrm{U}\right.$, $\mathrm{T}_{1 / 2} \approx 160.000$ jaar). Dit komt van nature niet op aarde voor: al het ${ }^{233} \mathrm{U}$ in de wereld werd geproduceerd in de jaren zestig van de vorige eeuw tijdens de nucleaire wapenwedloop van de koude oorlog [18, 19]. De beperkte beschikbaarheid is de belangrijkste reden dat ${ }^{225} \mathrm{Ac}$ nog zo weinig in studies en compassionate use programma's toegepast wordt. Daarom wordt er gezocht naar andere methoden om ${ }^{225} \mathrm{Ac}$ te produceren, bijvoorbeeld in een cyclotron. Naarmate de klinische behoefte aan ${ }^{225} \mathrm{Ac}$ groeit, wordt de stimulans om alternatieve productiemethoden te ontwikkelen groter $[20,21]$.

Daarnaast wordt er gekeken naar andere alfastralers. In 2018 is er zelfs al een fase I-studie geïnitieerd door BAYER met een tegen PSMA gericht monoklonaal antilichaam, dat is gelabeld met de alfastraler thorium-227 ( $\left.{ }^{227} \mathrm{Th}\right)$ (NCT03724747). Antilichamen hebben in het algemeen een veel langere circulatietijd dan de kleine op PSMA gerichte peptiden, die gebruikt worden bij PSMA-PET/CT, ${ }^{177} \mathrm{Lu}-\mathrm{PSMA}-$ en ${ }^{225}$ Ac-PSMA-therapie. Daarentegen is de halfwaardetijd van ${ }^{227}$ Th met 19,7 dagen als lang te bestempelen, waardoor mogelijk toch een hoge tumoropname met beperkte toxiciteit bereikt kan worden [5, 22]. Bovendien komen bij het verval van ${ }^{227}$ Th meerdere alfadeeltjes vrij (enigszins vergelijkbaar met ${ }^{225} \mathrm{Ac}$ ), hetgeen aantrekkelijk is, mits deze wel in de tumor vrijkomen en niet re-distribueren naar gezonde organen [23, 24].

In preklinisch onderzoek worden PSMA-liganden ook gelabeld met andere alfastralers, zoals terbium$149\left({ }^{149} \mathrm{~Tb}\right)$ [25], astatine-211 ( $\left.{ }^{211} \mathrm{At}\right)[26,27]$ en lood$212\left({ }^{212} \mathrm{~Pb}\right)$ [28-30], maar ook deze isotopen worden nog niet grootschalig geproduceerd. Het onderzoek naar de ontwikkeling van ${ }^{212} \mathrm{~Pb}$-PSMA-therapie vindt overigens onder andere plaats bij het Nederlandse NRG (te Petten). ${ }^{212} \mathrm{~Pb}$ heeft door zijn halfwaardetijd van 10,6 uur veel potentie voor radionuclide therapie. Hoewel op productievlak nog veel onderzoek nodig is, is er door de toegenomen vraag naar alfastralers wel meer aandacht gekomen voor het verbeteren van de beschikbaarheid van alfastralers.

\section{Conclusie}

Bij de meeste studies met PSMA-radioligandtherapie is ${ }^{177} \mathrm{Lu}$-PSMA gebruikt, een bètastraler. Het gebruik van een alfastraler zoals ${ }^{225} \mathrm{Ac}$-PSMA heeft echter vanuit theoretisch oogpunt voordelen; alfastralers leiden tot moeilijker te herstellen DNA-schade en hebben daardoor vermoedelijk een grotere effectiviteit en een betere immunologische respons. Door het geringe doordringende vermogen van alfastralers lijkt het ook haalbaar om patiënten met diffuse beenmergmetastasering en patiënten met microscopische metastasen met alfa-PSMA-therapie te behandelen. Echter, er zijn slechts enkele kleine retrospectieve series gepubliceerd en nog geen vergelijkende studies. Hoewel deze eerste resultaten veelbelovend zijn, blijft het gebruik van alfa-PSMA-therapie voorlopig nog hoogst experimenteel. De bijwerking van alfa-PSMA-therapie op de speekselklieren is waarschijnlijk ook ernstiger dan die van bèta-PSMA-therapie, waardoor de dose- 
ring van ${ }^{225} \mathrm{Ac}$ voorzichtig dient te gebeuren. Omdat er geen goede beschermende interventies zijn voor de speekselklieren, wordt de oplossing vooralsnog gezocht in combinaties van ${ }^{177} \mathrm{Lu}$-PSMA en ${ }^{255} \mathrm{Ac}$-PSMA en de-escalatieschema's met in opeenvolgende cycli een afnemende ${ }^{225} \mathrm{Ac}$-dosering. Daarnaast is de beschikbaarheid van geschikte alfastralers een wereldwijd probleem en wordt er naarstig gezocht naar alternatieve grootschaligere productiemethoden.

Open Access This article is distributed under the terms of the Creative Commons Attribution 4.0 International License (http://creativecommons.org/licenses/by/4.0/), which permits unrestricted use, distribution, and reproduction in any medium, provided you give appropriate credit to the original author(s) and the source, provide a link to the Creative Commons license, and indicate if changes were made.

\section{Literatuur}

1. Smits M, Gerritsen W, Mehra N. Future therapeutic strategies for metastatic prostate cancer. Tijdschr Urol. 2019;9(6):117-30.

2. Ghosh A, Heston WD. Tumor target prostate specific membrane antigen (PSMA) and its regulation in prostate cancer. JCell Biochem. 2004;91(3):528-39.

3. Silver DA, Pellicer I, Fair WR, Heston WD, Cordon-Cardo C. Prostate-specific membrane antigen expression in normal and malignant human tissues. Clin Cancer Res. 1997;3(1):81-5.

4. Kalmthout LWM van, Sar ECA van der, Braat AJAT, Keizer B de, Lam MGEH. Lutetium-177-PSMA therapy for prostate cancer patients-a brief overview of the literature. Tijdschr Urol. 2020. https://doi.org/10.1007/s13629-02000297-5.

5. Haberkorn U, Giesel F, Morgenstern A, Kratochwil C. The future of radioligand therapy: alpha, beta, or both? J Nucl Med. 2017;58(7):1017-8.

6. Kratochwil C, Haberkorn U, Giesel FL. (225)Ac-PSMA617 for therapy of prostate cancer. Semin Nucl Med. 2020;50(2):133-40.

7. Thomas P, Tracy B, Ping T, et al. Relative biological effectiveness (RBE) of alpha radiation in cultured porcine aortic endothelial cells. Int J Radiat Biol. 2007;83(3):171-9.

8. Kratochwil C, Bruchertseifer F, Rathke H, et al. Targeted Alpha Therapy of mCRPC with 225Actinium-PSMA-617: dosimetry estimate and empirical dose finding. J Nucl Med. 2017;58(10):1624-31.

9. Kratochwil C, Bruchertseifer F, Rathke H, et al. Targeted alpha-therapy of metastatic castration-resistant prostate cancer with (225)Ac-PSMA-617: swimmer-plot analysis suggests efficacyregardingduration oftumorcontrol. JNucl Med. 2018;59(5):795-802.

10. Sathekge M, Bruchertseifer F, Vorster M, et al. Predictors of overall and disease-free survival in metastatic castrationresistant prostate cancer patients receiving (225)Ac-PSMA617 radioligand therapy. J Nucl Med. 2020;61(1):62-9.

11. Sathekge M, Bruchertseifer F, Knoesen O, et al. 225AcPSMA-617 in chemotherapy-naive patients with advanced prostate cancer: a pilot study. Eur J Nucl Med. 2019;46(1):129-38.

12. Khreish F, Ebert N, Ries M, et al. (225)Ac-PSMA617/(177)Lu-PSMA-617 tandem therapy of metastatic castration-resistant prostate cancer: pilot experience. Eur J Nucl Med Mol Imaging. 2020;47(3):721-8.
13. Kratochwil C, Bruchertseifer F, Giesel FL, et al. 225AcPSMA-617 for PSMA-targeted alpha-radiation therapy of metastatic castration-resistant prostate cancer. J Nucl Med. 2016;57(12):1941-4.

14. Kratochwil C, Giesel FL, Bruchertseifer F, et al. (2)(1)(3)BiDOTATOC receptor-targeted alpha-radionuclide therapy induces remission in neuroendocrine tumours refractory to beta radiation: a first-in-human experience. Eur J Nucl Med Mol Imaging. 2014;41(11):2106-19.

15. Malcolm J, Falzone N, Lee BQ, Vallis KA. Targeted radionuclide therapy: new advances for improvement of patient management and response. Cancers. 2019;11(2):268.

16. Rahbar K, Ahmadzadehfar H, Kratochwil C, et al. German multicenter study investigating 177Lu-PSMA-617 radioligand therapy in advanced prostate cancer patients. J Nucl Med. 2017;58(1):85-90.

17. Hofman MS, Violet J, Hicks RJ, et al. [(177)Lu]-PSMA617 radionuclide treatment in patients with metastatic castration-resistant prostate cancer (LuPSMA trial): a single-centre, single-arm, phase 2 study. Lancet Oncol. 2018;19(6):825-33.

18. Chakravarty R, Siamof CM, Dash A, Cai W. Targeted $\alpha$-therapy of prostate cancer using radiolabeled PSMA inhibitors: a game changer in nuclear medicine. Am J Nucl Med Mol Imaging. 2018;8(4):247-67.

19. Robertson AKH, Ramogida CF, Schaffer P, Radchenko V. Development of (225)Ac radiopharmaceuticals: TRIUMF perspectives and experiences. Curr Radiopharm. 2018;11(3):156-72.

20. Bruchertseifer F, Kellerbauer A, Malmbeck R, Morgenstern A. Targeted alpha therapy with bismuth-213 and actinium-225: Meeting future demand. J Labelled Comp Radiopharm. 2019;62(11):794-802.

21. Apostolidis C, MolinetR, McGinleyJ, Abbas K, MollenbeckJ, MorgensternA.Cyclotron production of Ac-225 for targeted alpha therapy. Appl Radiat Isot. 2005;62(3):383-7.

22. Muselaers CHJ, Boers-Sonderen MJ, Oostenbrugge TJ van, et al. Phase 2 study of lutetium 177-labeled anti-carbonic anhydrase ix monoclonal antibody girentuximab in patients with advanced renal cell carcinoma. Eur Urol. 2016;69(5):767-70.

23. Hammer S, Hagemann UB, Zitzmann-Kolbe S, et al. Preclinical efficacy of a PSMA-targeted thorium-227 conjugate (PSMA-TTC), a targeted alpha therapy for prostate cancer. Clin Cancer Res. 2020;26(8):1985-96.

24. Frantellizzi V, Cosma L, Brunotti G, et al. Target alpha therapy with thorium-227. Cancer Biother Radiopharm. 2020; https:// doi.org/10.1089/cbr.2019.3105.

25. Umbricht CA, Köster U, Bernhardt P, et al. Alpha-PET for prostate cancer: preclinical investigation using $149 \mathrm{~Tb}$ PSMA-617. Sci Rep. 2019;9(1):17800.

26. Kiess AP, Minn I, Vaidyanathan G, et al. (2S)-2-(3-(1-carboxy-5-(4-211At-astatobenzamido)pentyl)ureido)-pentanedioic acid for PSMA-targeted alpha-particle radiopharmaceutical therapy. J Nucl Med. 2016;57(10):1569-75.

27. GuérardF, Gestin J-F, Brechbiel MW. Production of [(211)At]astatinated radiopharmaceuticals and applications in targeted $\alpha$-particle therapy. Cancer Biother Radiopharm. 2013;28(1):1-20.

28. Santos JC dos, Schäfer M, Bauder-Wüst U, et al. Development and dosimetry of $203 \mathrm{~Pb} / 212 \mathrm{~Pb}$-labelled PSMA ligands: bringing "the lead" into PSMA-targeted alpha therapy? Eur J Nucl Med Mol Imaging. 2019;46(5):1081-91.

29. Banerjee SR, Minn I, Kumar V, et al. Preclinical evaluation of $(203 / 212) \mathrm{Pb}$-labeled low-molecular-weight compounds for targeted radiopharmaceutical therapy of prostate cancer. J Nucl Med. 2020;61(1):80-8. 


\section{Artikel}

30. Stenberg VY, Juzeniene A, Chen Q, Yang X, Bruland OS, Larsen RH. Preparation of the alpha-emitting PSMA targeted radioligand [(212) $\mathrm{Pb}] \mathrm{Pb}-\mathrm{NG001}$ for prostate cancer. JLabelled Comp Radiopharm. 2020;63(3):129-43.

31. HeckMM, Tauber R, Schwaiger S, et al. Treatment outcome, toxicity, and predictive factors for radioligand therapy with ${ }^{177} \mathrm{Lu}$-PSMA-I\&;T in metastatic castration-resistant prostate cancer. Eur Urol. 2019;75(6):920-6.

drs. Bastiaan M. Privé, arts-onderzoeker

dr. Willemijn A.M. van Gemert, nucleaire geneeskundige in opleiding prof. dr. James Nagarajah, nucleair geneeskundige dr. Niven Mehra, internist oncoloog

prof. dr. Winald R. Gerritsen, internist oncoloog, hoogleraar Immunotherapie

dr. Inge M. van Oort, uroloog

prof. dr. Martin Gotthardt, nucleair geneeskundige, hoogleraar Experimentele Nucleaire Geneeskunde

dr. Sandra Heskamp, onderzoeker

dr. Marcel J.R. Janssen, nucleairgeneeskundige 